\title{
Visual loss from mismanaged ocular injury with foreign body impaction: A Case Report

\author{
Akintoye $\mathrm{IO}^{1}$, Adeoti $\mathrm{CO}^{* 2}$
}

${ }^{1}$ Eye Clinic, JolaOlu Specialist Hospital, Osogbo, Nigeria.

${ }^{2}$ Department of Ophthalmology, Ladoke Akintola University of Technology Teaching Hospital, Osogbo, Nigeria.

*Correspondence: Professor CO Adeoti, Department of Ophthalmology, College of Health Sciences,

Ladoke Akintola University of Technology Teaching Hospital, Osogbo, Nigeria; P.O Box 979, Osogbo, Osun

State, Nigeria. Email: caroladeoti2001@yahoo.co.uk;

ORCID - http://orcid.org/0000-0002-7530-8216.

\section{Summary}

Ocular injury occurs commonly and it may lead to visual impairment if it is not properly managed. We report the case of a 35-year old man with a retained infected ocular foreign body in his right eye following an injury. The foreign body was not discovered despite consulting non-ophthalmologists at a Maternity Centre and an Optical Shop over a period of ten days. At presentation at the Specialist Hospital, he was unable to see with swelling of the eyelid, red eye and discharge. On examination, the visual acuity in the affected eye was NLP and an infected stick that penetrated the eyeball was discovered in the superonasal aspect of sclera covered by the swollen upper lid. This resulted in endophthalmitis, cataract and blindness of that eye.

Ocular injuries must be promptly referred to the ophthalmologist for appropriate care and to prevent complications. The case clearly showed a diagnostic and therapeutic challenge for paramedics who encounter eye injuries outside the tertiary hospital setting. Therefore, this report raises public health concern intended to increase awareness on the management of eye injuries.

The incorporation of Primary Eye Health into Primary Health Care along with training and re-training of Community Health Extension Workers, General Practitioners and other rural health workers cannot be overemphasized.

Keywords: Endophthalmitis, Ocular injuries, Ophthalmologic Emergency Care, Visual loss.

\section{Introduction}

Ocular injury occurs all over the world. [1] It is an important cause of visual impairment [2] and a reason for ophthalmic services utilization. [3] Injuries are responsible for 1 in 20 eye conditions seen by ophthalmologists in a busy eye emergency clinic in the United Kingdom. [2]
Ocular injury characteristically occurs in only one eye in the majority of cases (98\%), [4] thereby, causing monocular blindness. [5, 6] However, bilateral blindness has been reported in some instances. [7]

The workplace, which includes agricultural settings, has been found to be commonplaces of injury, especially in developing countries. [8] In Nigeria, ocular injuries are commonly associated 
with farming activities; sticks/twigs (41.1\%) were reported as the commonest agents of ocular trauma among the elderly. [9] The home had been reported as the most frequent $(60 \%)$ place of occurrence of ocular injuries among hospitalized elderly people in Scotland with falls $(44 \%)$ as the most common predisposition to ocular trauma among the elderly. [10] In Pakistan, about $92 \%$ of ocular injuries were sustained in industrial areas among males while $8.6 \%$ occurred among women at home from burns and domestic fights. ${ }^{[8]}$

Pointed objects, including canes, have been noted to cause eye injuries in $41.2 \%{ }^{[11]}$ and $43.8 \%$ [12] of cases as reported by Onyekonwu et al in Abakaliki, and Ashaye in Ibadan respectively, both in Nigeria. Pointed objects are known to readily perforate the eyeball. In Pakistan, Mohammad Idris et al, [8] reported small, elongated, pointed objects to be responsible for most cases of retained intraocular foreign body. In addition, agents such as pieces of wood and stone, being very dirty, were associated with endophthalmitis and poor final visual acuity. Some of the various complications of ocular trauma reported in the literature [8] such as traumatic hyphaema, cataract, vitreous haemorrhage, endophthalmitis and retinal detachment can also cause blindness.

Ocular injury resulting from the use of canes to drive animals away has not been reported in the literature. Therefore, this report is about the case of ocular injury which was inappropriately managed by non-ophthalmologists. To the best of our knowledge, this is unknown in the literature.

The objective of this report is to highlight the problem of managing eye injuries by allied health workers and the need for the training and re-training of such group of health workers. This report may also reinforce the call for the incorporation of eye health care into primary health care.

\section{Case Description}

A 35-year old man, who was a barber, presented at the hospital with the inability to see, swelling of the eyelid, red eye and eye discharge following a stick injury to the right eye and eyelid. The injury was sustained while he was using a cane to drive a goat away ten days before presentation. He bled from the lid and the eye immediately following the injury. $\mathrm{He}$ presented immediately at a nearby Maternity Health Center where eye drops (unidentified) were prescribed but without improvement. Four days later, he sought further care from an optician who prescribed chloramphenicol ointment, some oral drugs (such as ciprofloxacin tablet 500mg twice a day, vitamin B complex and vitamin $C$ tablets) and other eye drops to no avail. The patient presented in our private specialist centre on account of eye pain and lack of improvement in the other symptoms including his vision. His pre-morbid visual state revealed that he had no previous history of eye disease and he was not wearing eyeglasses. He was not a known hypertensive, diabetic or asthmatic patient.

On examination, the visual acuity was 'No light perception (NLP)' in the right eye but $6 / 5$ in the left eye. There was right peri-orbital oedema, conjunctival hyperaemia, ciliary injection and perforated globe. There was a stick in the sclera which was covered with exudates and hiding under the upper eyelid supero-nasally (Figure 1). Slit lamp examination showed, in addition, blood clots and exudate in the anterior chamber and pupillary orifice. The posterior segment could not be visualized. The left eye was essentially normal. Intraocular pressure was $6 \mathrm{mmHg}$ and $14 \mathrm{mmHg}$ on the right and left respectively. His vital signs were normal and the 
packed cell volume was $38 \%$. A tentative diagnosis of a retained intraocular foreign body with endophthalmitis, hypotony was made and to exclude retinal detachment in the right eye.

Ocular ultrasonography was done since the patient could not afford Computerized Tomography and Magnetic Resonance Imaging was not available. Microscopy, culture and sensitivity of conjunctival swab did not yield any growth. Nevertheless, he was placed on the following medications: intramuscular Antitetanus Serum injection 1500units after a test dose and intramuscular injection of Tetanus toxoid $0.5 \mathrm{ml}$, sub-conjunctival gentamycin $20 \mathrm{mg}$ 12 hourly, intravenous metronidazole $500 \mathrm{mg}$ 8hourly, intravenous ceftriaxone sodium 1 gram daily, topical drops of amoxicillin (antibiotic) 2

Microscopy, culture and sensitivity of the vitreous tap swab yielded Staphylococcus aureus sensitive to flucloxacillin, a beta-lactam antibiotic. Therefore, intravenous ceftriaxone (cephalosporin antibiotic) was administered for hourly, diclofenac (non-steroidal antiinflammatory drug), $1 \% \quad$ atropine (cycloplegic/dilating drug) twice daily and natamycin (antifungal agent) 5 times daily. He was also scheduled for foreign body removal and intra-vitreal injection of vancomycin.

Ultrasound scan reported a longitudinal echogenic foreign body measuring $2.47 \mathrm{~cm}$ in length with surrounding echogenic material in the vitreous cavity. Intra-operatively, copious, purulent discharge oozed out of the sclera opening when the foreign body was removed. Figure 2 shows the foreign body after removal. Vitreous tap was done and intra-vitreal vancomycin $2 \mathrm{mg}$ was administered. The scleral opening was sutured with $8 / 0$ virgin's silk material.

four days and thereafter, was changed to a combination of oral amoxicillin $250 \mathrm{mg}$ and flucloxacillin 250mg caplets 6-hourly for ten days. When he was reviewed a month after surgery, the patient had no more pains but he had leukocoria and the vision remained NLP.

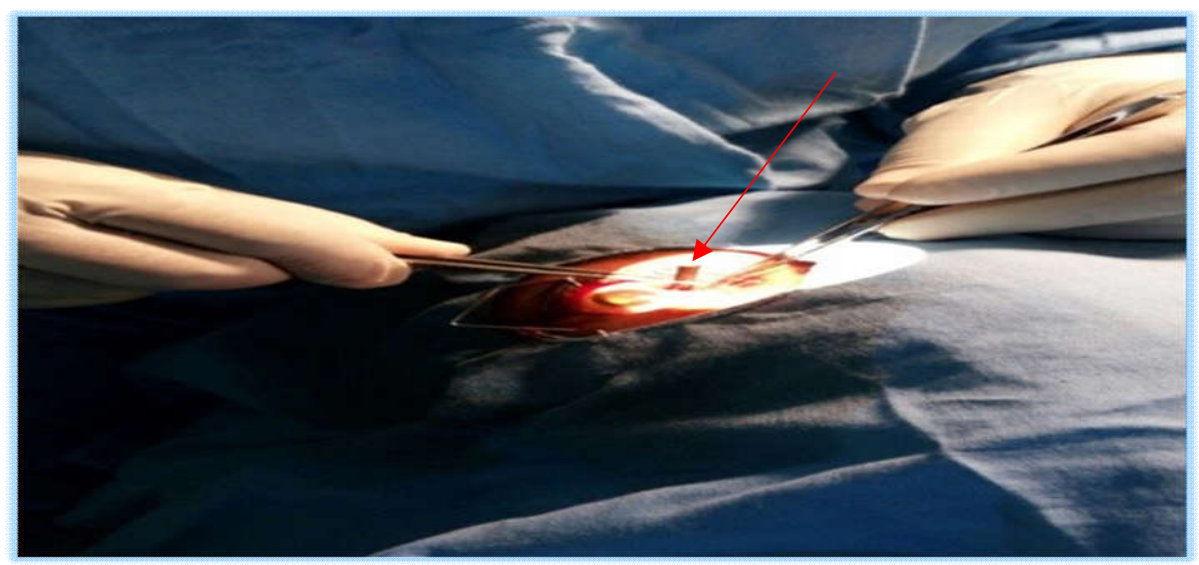

Figure 1: The foreign body in the sclera just before it was removed in the theatre. A speculum is in place and cornea is to the left of picture or right of surgeon towards the outer canthus. The red arrow is pointing to the foreign body.

\section{Ethical considerations}

This report strictly followed the tenets of the declaration of Helsinki. A verbal informed consent was also obtained from the patient for use of his data including the eye photographs, 
for publication after explaining to him that only

\section{Discussion}

Ocular injuries are important and preventable public health problems. Globally, it is the leading cause of unilateral blindness. ${ }^{[13]}$ Primary eye health care is still not fully incorporated into primary health care in Nigeria. The populace does not seek eye health care early and inappropriate places. This may be due to poverty, lack of awareness of appropriate facilities within reach or the absence of eye specialists in rural areas. In Nigeria, eye specialists are concentrated in urban centres. [14] In a report on sub-Saharan Africa, the eye health workforce in Africa was found to be smaller and less dense than other regions of the world and the affected eye will be displayed. unevenly distributed within countries. [15] In Nigeria, it was estimated that there were 2.6 ophthalmologists per million population and these were all concentrated in urban centres. [14] This is far from being adequate. In order to achieve vision 2020 (an initiative to provide vision for all by the year 2020), a ratio of 4 ophthalmologists per million population has been recommended. [14] The incorporation of primary eye health care into primary healthcare in Nigeria cannot be overemphasized. This will involve training and re-training of community health workers in recognition, first aid care and indications for prompt referral of serious eye conditions including injuries.

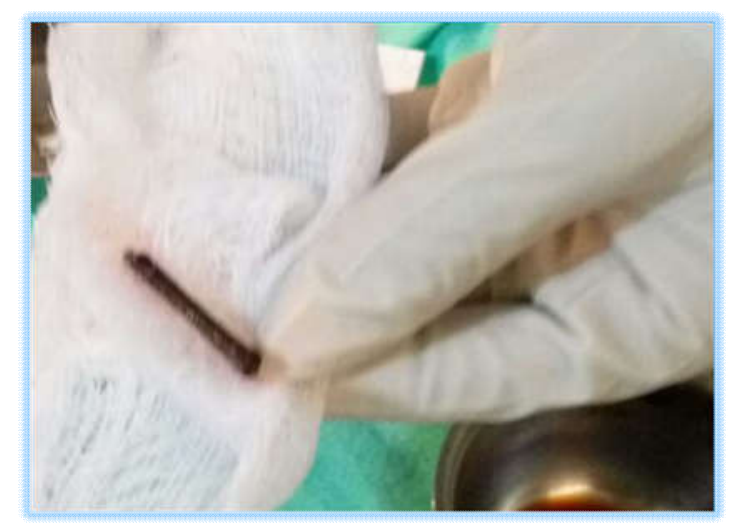

Figure 2: The foreign body after removal

The index patient sought care at a primary health centre and an optical shop but did not have the necessary detailed eye examination which can discover the foreign body lodged under the swollen upper lid, or receive adequate treatment and prompt referral to a specialist centre. The patient went from a maternity centre to an optical shop and finally, the ophthalmologist after ten days of retention of an infected intra-ocular foreign body. Unfortunately, by that time the patient had completely lost his vision from endophthalmitis.
If the index patient had presented or was referred to an ophthalmologist earlier, he would have benefited from a detailed eye examination and early diagnosis with appropriate interventions, including vitreoretinal surgery to salvage the vision.

Eye injuries are best managed by the ophthalmologists. This is because a serious eye injury may not be obvious to nonophthalmologists at the onset and may result in blindness if not properly managed. However, if 
ophthalmologists are not readily available, minor eye injuries can be managed by nonspecialists such as family physicians, optometrists, emergency physicians but when there is severe continuous pain, bleeding, reduced visual acuity or if there are doubts as to the impact of the injury on the structure and function of the eye, the patient should be immediately referred to the ophthalmologist. This necessitates training and re-training of primary health care workers in the recognition of serious eye diseases, especially ocular trauma since this class of health care providers are usually the first contacts of patients in the community. It is also necessary for the government to introduce enforce policies which will regulate the activities of all primary health care workers such as optical vendors.

The places of injury, size and nature of intraocular foreign bodies have been found to be associated with loss of vision, especially in developing countries. For instance, unilateral loss of vision was attributed to the workplace such as agriculture. [16, 17] Foreign bodies such as pieces of wood and stone are associated with endophthalmitis. ${ }^{[18]}$ This is similar to the case in the index report. The final visual outcome has also been found to be dependent on the size and shape of the foreign body. Large elongated intra-ocular foreign bodies have been reported to be associated with poor final visual acuity. $[19,20]$ The index patient had a $2.47 \mathrm{~cm}$ long stick in the eye for ten days prior to presentation to the Ophthalmologist. Late presentation or late referral of patients to the ophthalmologist contributes to the poor visual prognosis following penetrating and perforating eye injuries. [11, 12, 21] Therefore, it is not surprising that the visual acuity of the index patient was NLP at presentation. ${ }^{[22,23]}$ Non-specialists have been advised to avoid delaying referral of patients with eye injuries especially if there is a suspicion of ocular penetration, even when such injuries are caused by everyday objects, such as writing instruments. [24]

The role of prevention in eye health promotion is also very important. This can be achieved by raising community awareness and involvement. [25] Wearing protective eyeglasses can reduce the incidence of ocular injury, especially in those who use canes to rear animals. [26] If the index patient in this report had worn protective eyeglasses, the injury could have been averted.

\section{Conclusion}

Delayed and inappropriate specialist management of ocular injuries may be complicated by endophthalmitis and eventual visual loss. Ocular injuries must be promptly referred to the ophthalmologist for appropriate intervention. As a matter of urgency, there is a need to incorporate primary eye care into primary health care with training and retraining of community health extension workers, general and private practitioners, opticians and other health officers.

Authors' Contributions: Both authors were involved in the conceptualization and writing of the report. Conflict of Interest: None declared. Funding: Self-funded.

Publication History: Submitted 01-June 2018; Revised 23-July 2018; Accepted 28-September 2018.

\section{References}

1. Adeoti CO, Ashaye AO, Ubah JN. The dangers of bunk beds to the eye- A Case Report and Preventive Measures. Niger Postgrad Med J 2010; 17(2): 172-4.

2. Mac Ewen CJ. Eye injuries: a prospective survey of 5671 cases. Br J Ophthalmol 1989; 73: 888-894. 
3. Schein OD, Hibberd PL, Shingleton BJ, et al. Spectrum and burden of ocular injury. Ophthalmology 1986; 95(1): 300-5.

4. Murdoch IE, Morris SS, Cousens SN. People and eyes: statistical approaches in ophthalmology. Br J Ophthalmol 1998; 82 (8): 971-3.

5. Nwosu SN. Blindness and visual impairment in Anambra state Nigeria. Trop Geogr Med 1994; 46(6): 346-9.

6. Elebusunu M. Aetiology of childhood blindness in Benin-City, Nigeria. Public Health. 1987; 101(1): 59-62.

7. Adeoti CO, Bello TO, Ashaye AO. Blinding ocular injuries. Niger J Surg Sci 2004; 14(2): 44-6.

8. Soni M, Khan IU, Jadoon Z. The pattern of ocular trauma in patients at Govt. Naseerullah Khan Babar Memorial Hospital, Peshawar (A study from 2010-2014). Ophthalmol Update. 2015; 13(4): 271-5.

9. Onakpoya $\mathrm{OH}$, Adeoye A, Adeoti CO, Ajite K. Epidemiology of ocular trauma among the elderly in a developing country. Ophthalmic Epidemiol 2010; 17(5): 315-20.

10. Desai P, MacEwen CJ, Baines P, Minaissian DC. Epidemiology and implications of ocular trauma admitted to hospital in Scotland. J Epidemiol Community Health 1996; 50(4): 436-41.

11. Onyekonwu GC, Chuka-Okosa CM. Pattern and visual outcome of eye injuries in children at Abakaliki, Nigeria. West Afr J Med 2008; 27(3): 152-4.

12. Ashaye AO. Eye injuries in children and adolescents: A report of 205 cases. J Natl Med Assoc 2009; 10(1): 51-6.

13. Thylefors B. Epidemiological patterns of ocular trauma. Aust N Z J Ophthalmol 1992; 20(1): 95-8.
14. Palmer JJ, Chinanayi F, Gilbert A, Pillay D, Fox S, Jaggernath $\mathrm{J}$, et al. Trends and implications for achieving VISION 2020 human resources for eye health targets in 16 countries of sub-Saharan Africa by the year 2020. Human Resources Health 2014; 12(1): 45.

15. Palmer JJ, Chinanayi F, Gilbert A, Pillay D, Fox S, Jaggernath J, et al. Managing human resources for eye health in 21 countries of sub-Saharan Africa: Current progress towards Vision 2020. Human Resource Health 2014; 12(1): 44.

16. Jonas JB, Knorr HL, Budde WM. Prognostic factors in ocular injuries caused by intraocular or retrobulbar foreign bodies. Ophthalmology 2000; 107: 823-8.

17. Wong TY, Seet MB, Ang CL. Eye injuries in twentieth-century warfare: a historical perspective. Surv Ophthalmol 1997; 41: 43359.

18. Idris I, Alam M, Masud MZ, Yaqoob $\mathrm{H}$. Clinical and morphological characteristics of IOFB presented to a Tertiary Care Centre of Khyber Pakhtunkhwa. Ophthalmol Update 2015; 13(4): 258-61.

19. Groess 1S, Nanda SK, Mieler WF. Assaultrelated penetrating ocular injury. Am J Ophthalmol 1993; 15(116): 26-33.

20. Napora KJ, Obuchowska I, Sidorowicz A, Mariak Z. [Intraocular and intraorbital foreign bodies characteristics in patients with penetrating ocular injury]. Klin Oczna 2009; 111: 307-12.

21. Adeoye AO. Eye injuries in the young in IleIfe, Nigeria. Niger J Med 2002; 11(1): 26-9.

22. Han SB, Yu HG. Visual outcome after open globe injury and its predictive factors in Korea. J Trauma. 2010; 69: E66-72. 
Akintoye IO, et al

23. YalcinTök O, Tok L, Eraslan E, Ozkaya D, Ornek F, Bardak Y. Prognostic factors influencing final visual acuity in open globe injuries. J Trauma 2011; 71: 1794-800.

24. Kelly SP, Reeves GMB. Penetrating eye injuries from writing instruments. Clin Ophthalmol 2012; 6(1): 41-4.
25. Green L W, Raeburn JM. Health. What is it? What will it become? Health Promotion. 1988; 3: 151-7.

26. Eye injuries. Dictionary of Sport and Exercise Science and Medicine by Churchill Livingstone. 2008. Retrieved January 30, 2018, from https://medical dictionary.thefreedictionary.com/eye+injuri es. 